\title{
Assessment Of Factors Involved In The Visual Choice Of Dental Color - Clinical Trials
}

ESJ Natural/Life/Medical Sciences

\section{Mihailescu Radu,}

University of Medicine, Pharmacy, Science and Tehnology (UMFST) Targu Mures Romania

Submitted: 06 September 2020

Accepted: 21 October 2020

Published: 31 October 2020

Corresponding author:

Mihailescu Radu

DOI: 10.19044/esj.2020.v16n30p211

Copyright 2020 Rdu et al.

Distributed under Creative Commons CC-BY 4.0 OPEN ACCESS
With the development of societies, the demands of patients in terms of dental aesthetics have increased. To keep up with the increasingly demanding requirements of patients, dentists have been researching the factors that influence positively or negatively the choice of dental color, in order to control them and to obtain the best aesthetic results.Purpose of the study:Whether there is a correlation between choice time and accuracy. Whether there are differences in time and accuracy in determining with the Vita Classical key compared to the Vita Linear Guide.Material and Methods:This study involved 30 students (10 males and 20 females) of the University of Medicine and Pharmacy "Iuliu Hațieganu" ClujNapoca from the second to sixth year of study, aged 19-26. Of these, 18 (5 males and 13 females) were included and participated in the study itself. The participants were asked to determine the dental color of 1.1; 1.2; 1.3 of a patient.

Results:In all three teeth color, both with the Vita Classical key and with the Vita Linear Guide key, no statistically significant correlation was found between the tooth color matching time and the matching accuracy.

Conclusions: 1. A3 color required a longer matching time than A2 and A3.5, however the differences were not statistically significant. 2M2 also required a longer determination time than 3M2, but the differences were not statistically significant.

2. No correlation was found between the time required to determine a color and the accuracy of its determination.

Subject: Dentistry

Keywords: Vita Classical, Vita Linear Guide, Matching Time, Matching

Accuracy) 


\section{Introduction:}

With the development of societies, the demands of patients in terms of dental aesthetics have increased. (Paravina, 2009).To keep up with the increasingly demanding requirements of patients, dentists have been researching the factors that influence positively or negatively the choice of dental color, in order to control them and to obtain the best aesthetic results (Dancy, Yaman, Dennison, O’Brein, \& Razzoog, 2003).

The studied factors were divided into observer-dependent factors (quality and condition of the visual analyzer, fatigue of the observer, age of the observer, experience and training of the observer, observation time) and observer-independent factors (type of incident lights, daylight hours the quality of the color keys, the color of the patient's skin, the color of the patient's clothes, his lips as well as the color of the walls in the dental office). (Chu, Trushkowsky, \& Paravina, 2010; A. J.McCullock, \& R. M. McCullock,1999)

Regarding the observation time, it was found that it is necessary to make short-term determinations (5 sec.), followed by a pause in which the doctor looks at a neutral color (green, gray) (Miller, 1993; Capa, 2010).

In this study the purpose was to determine:

1. whether a longer matching time is required for certain tooth colors;

2. accuracy of dental color determination for samples of different colors;

3. whether there is a correlation between choice time and accuracy;

4. whether there are differences in time and accuracy in determining with the Vita Classical key compared to the Vita Linear Guide.

\section{Main Text:}

\section{Material and Methods}

Observers:

This study involved 30 students (10 male and 20 female) of the University of Medicine and Pharmacy "Iuliu Haţieganu" Cluj-Napoca from the second to sixth year of study, aged 19-26. Of these, 18 (5 males and 13 females) were included and participated in the study itself.

Inclusion criteria:

- normal trichrome vision determined by the Ishihara test;

- good or very good ability to discriminate colors appreciated by discrimination tests.

The following materials were used for the inclusion tests in the study itself.

1. Study inclusion tests:

The 38 plates needed to determine some dyschromatopsies in the Ishihara test, light enclosure with gray background and standardized light 
D65, Vita Classical color key with masked samples, Vita Classical color key with uncovered samples.

2. The study itself:

Dental unit in position 1, with the light off, the patient whose tooth color is evaluated 1.1; 1.2; 1.3; soft part spacer; gray contrast, Smileline with corrected light kept at a distance of $10 \mathrm{~cm}$ from the patient's teeth; luxmeter; Vita Classical color key with masked samples; Vita Linear Guide 3D Master color key with masked samples; Vita Easy Shade spectrophotometer; stopwatch; fields, gloves, Mycrozid.

The participation of the observers in the study was conditioned by their passing through the two inclusion tests: the test for determining dyschromatopsies Ishihara, and the test for determining the ability to discriminate colors (calibration test).

The first test was the Ishihara test, where participants in the study were shown in turn various electronic drawings that contained either numbers or sinuous lines that connected two different points of a circle that participants had to recognize. The plates were displayed on a monitor in a dark room. These plates are constructed in such a way that in case of ailments, other numbers or symbols are perceived than normal.

To be included in the study, participants need a $100 \%$ recognition of numbers and lines, otherwise they will be excluded from the study on the grounds that they may suffer from a dyschromatopsia that can significantly influence the results of the study. Of the 30 participants in the study, 29 passed the Ishihara test and were accepted for the test to determine the ability to discriminate colors (calibration test).

The calibration test consists in determining the participants' ability to match the samples of two Vita Classical keys.

The participants were placed in a room without light, the only source of lighting being the enclosure with a gray background with standardized light D65. Where the matching of the samples of the two keys takes place.

Participants were placed in a sitting position at a distance of $30 \mathrm{~cm}$ from the center of the box, where the determination is made. The determination was made between the samples of a Vita Classical color key that has the symbols of the samples hidden in a random order known only by evaluators and not by participants and a Vita Classical color key with the symbols of the samples not covered.

Participants were not conditioned by time, accuracy being more important than speed. In order to proceed to the study itself, participants needed a success rate of at least $75 \%$ (at least 12 of the 16 samples must be correctly recognized). Of the 29 students left in the study after the 
Ishihara test, 18 passed the calibration test and were able to participate in the study itself, with good or very good ability to discriminate colors.

For the study itself, participants were asked to determine the dental color of 1.1; 1.2; 1.3 of a patient.

The determination of the dental color was done during one session in which the determination was performed with both color keys (Vita Classical and Vita Linear guide 3D Master), between 11:00 and 17:00. To standardize the results, the dental unit was positioned in position 1, with the doctor's seat placed in the lowest position

In order to exclude the influence of the oral cavity, a gray contraster was used for determinations and to standardize the light, a light source with corrected Smileline spectrum (5500K) with a light intensity of 1000 lux was used, determined with the help of the Light Meter device, which was obtained by positioning Smileline at $10 \mathrm{~cm}$ from the oral cavity.

With the contrast thus positioned, observers were influenced no longer by the color of the surrounding tissues, especially the tongue, and no unwanted shadows appeared that could influence the final decision of the observers.

Smile Line generates a standardized light, so regardless of the time of day, the light is the same during the determinations.

The color of the three teeth relevant to the study was determined by two methods:

1. Visually, with both color keys, by a doctor experienced in choosing dental color. Three determinations with Vita Classical and three determinations with Vita Linear Guide were performed for each tooth (1.1, 1.2 and 1.3).

2. Instrumentally, with the help of Vita Easyshade. 10 determinations were performed for each tooth (1.1, 1.2 and 1.3), recording the tooth color and CIELAB parameters, necessary for the calculation of color differences.

Thus, a result as close as possible to the natural color of the tooth was obtained, as a perfect match between the natural teeth and the color keys cannot be obtained, due to the different nature of the two evaluated objects:

-1.1: A3 (Vita Classical); 2M2 (Vita Linear Guide)

-1.2: A2 (Vita Classical); 2M2 (Vita Linear Guide)

-1.3: A3.5 (Vita Classical); 3M2 (Vita Linear Guide)

The test:

Initially, participants determined the color of the 1.1 tooth with Vita Classical, timing the duration of the determination (Fig. 1.1.). The color key samples are masked so that the observer cannot be influenced 
in any way in the determination with the Vita Linear Guide 3D Master key (Fig. 1.2.).

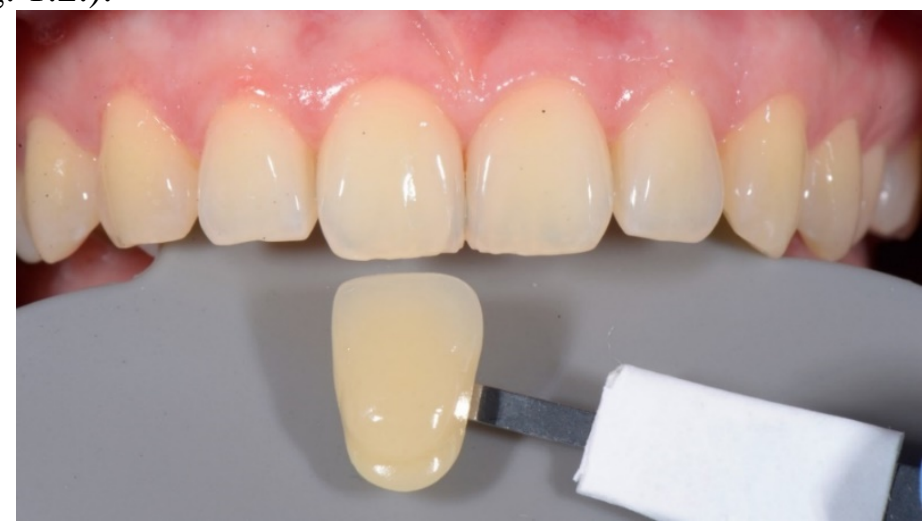

Fig. 1.1. Determination of tooth color 1.1 with Vita Classical

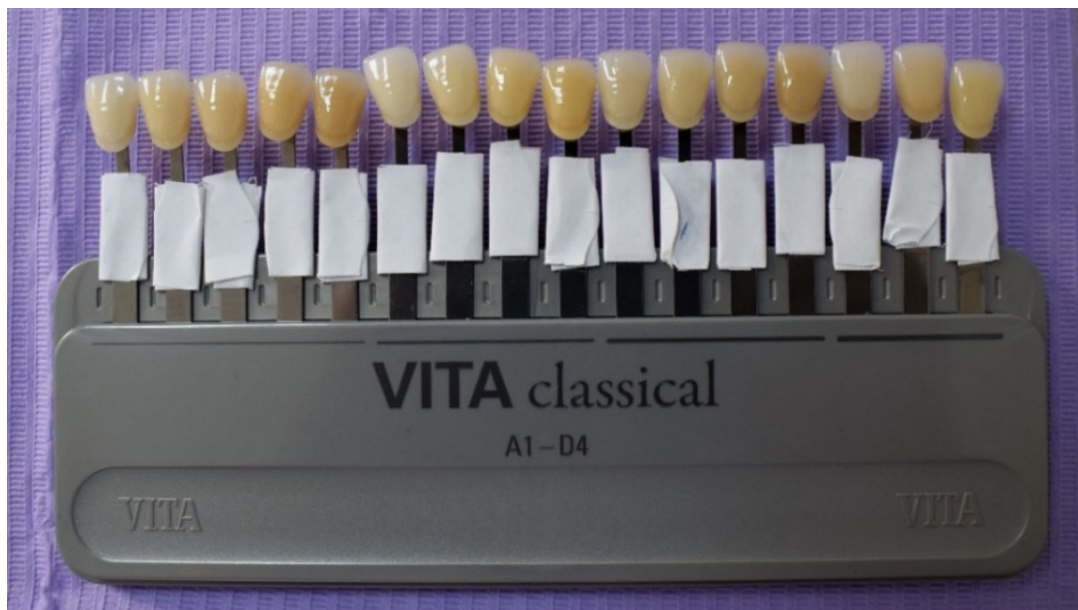

Fig. 1.2. Vita Classical key with hidden samples

After determining the color with Vita Classical for tooth 1.1, the participants also determined with Vita Classical the color of tooth 1.2 (Fig. 1.3.), Then moving on to tooth 1.3 (Fig. 1.4.). There was a 10second break between each combination so that the tooth enamel would not become dehydrated. 


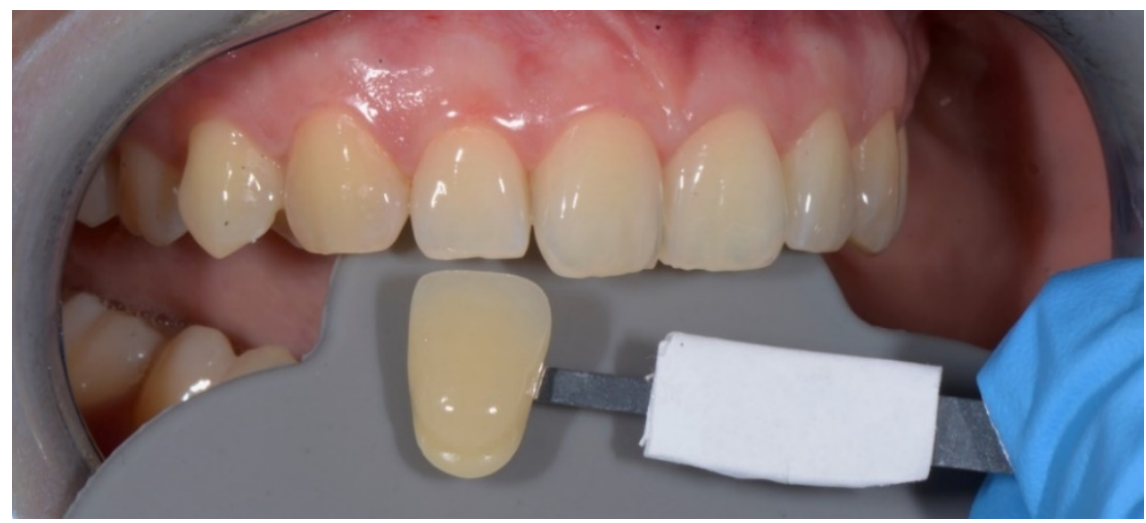

Fig. 1.3. Determination of tooth color 1.2 with Vita Classical

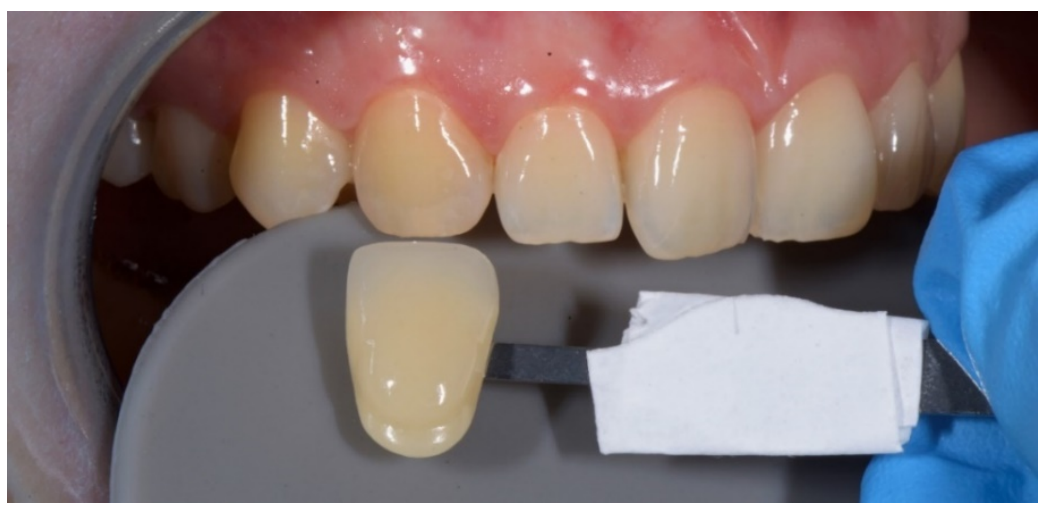

Fig. 1.4. Determining the color of the 1.3 tooth with Vita Classical

A matching time was recorded for each tooth, then the determination was performed with the Vita Linear Guide 3D Master. Following the same protocol, participants had a light source $10 \mathrm{~cm}$ away from the patient's teeth, the gray contrast was used and the matching time was measured at 1.1 (Fig. 1.5.) followed by a 10-second pause.

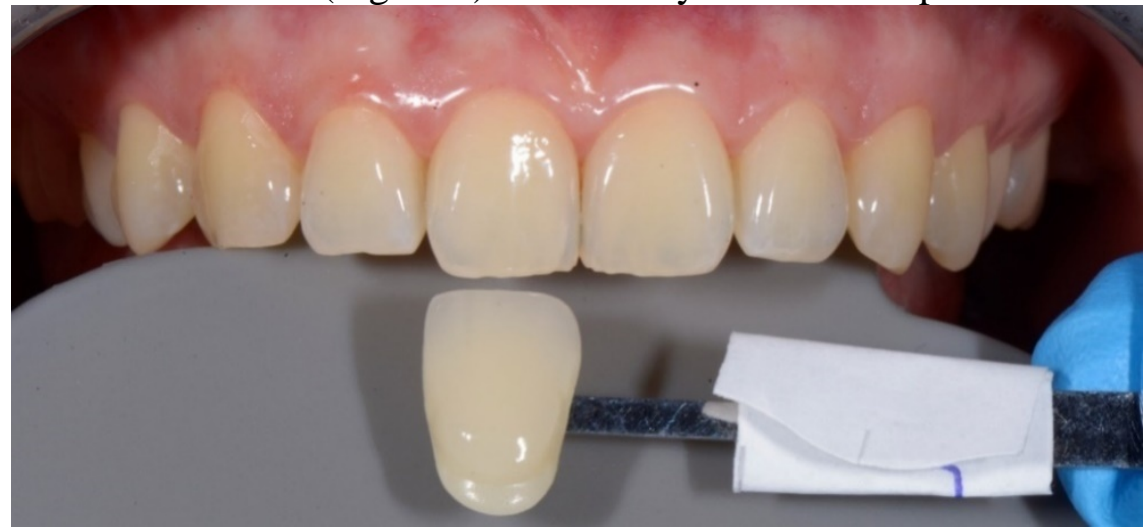

Fig. 1.5. Determining tooth color 1.1 with Vita Linear Guide 
This was followed by the determination of the color of tooth 1.2 (Fig. 1.6.) Followed by a pause of 10 seconds and finally the determination of the color of tooth 1.3 (Fig. 1.7.).

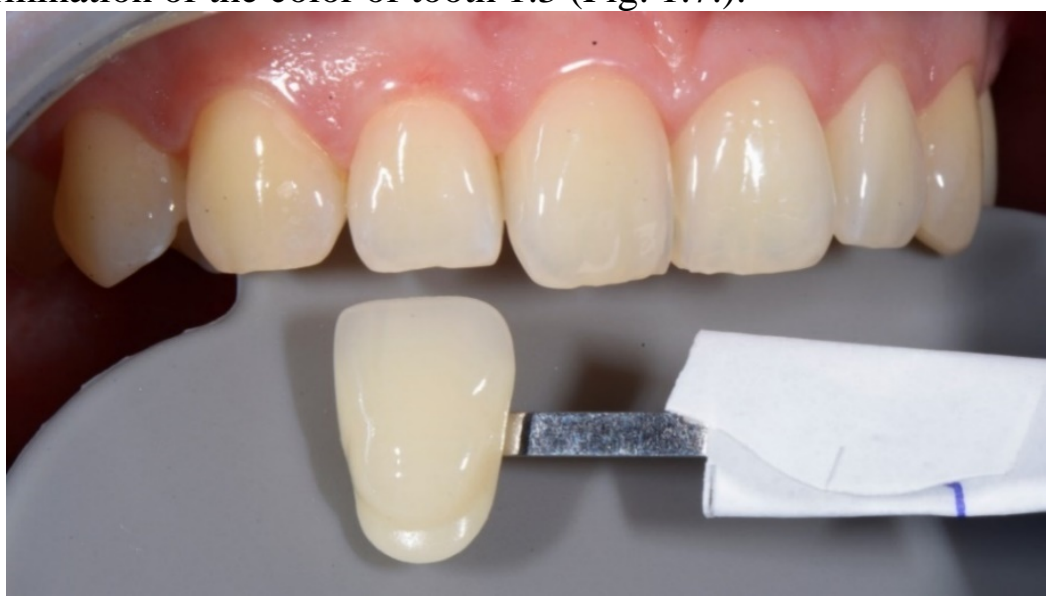

Fig. 1.6. Determining tooth color 1.2 with Vita Linear Guide

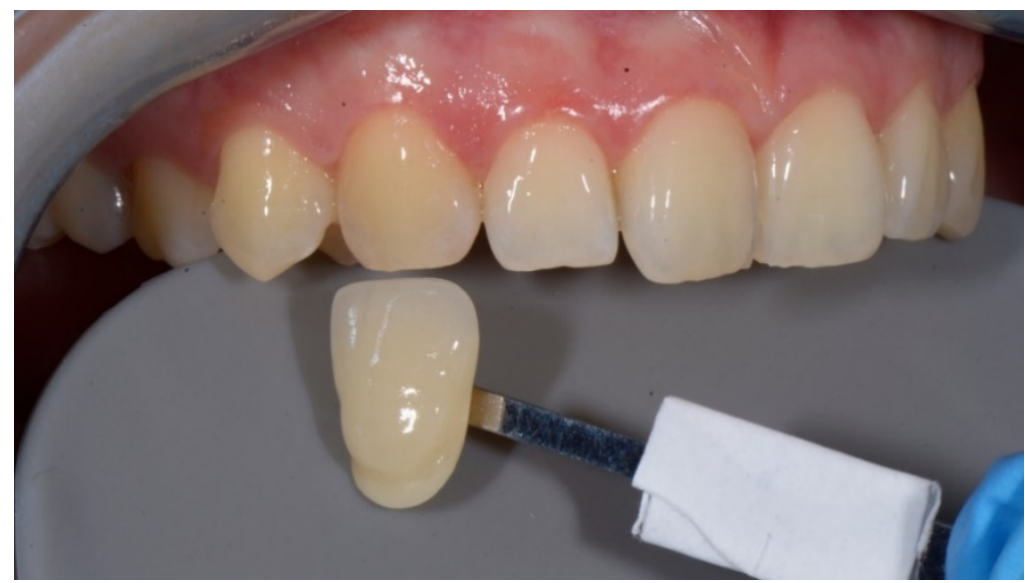

Fig. 1.7. Determining tooth color 1.3 with Vita Linear Guide

Also the samples of the Vita Linear Guide 3D Master key were masked (Fig. 5.20.). The matching time was recorded for each tooth and the data were entered in the tables. 


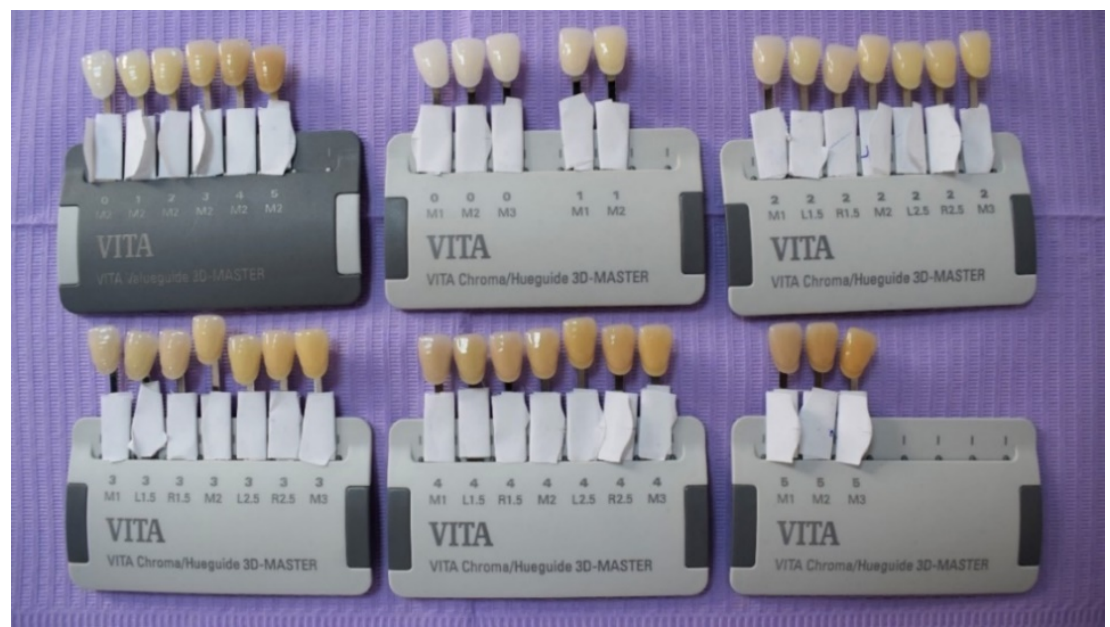

Fig. 5.20. Vita Linear Guide with masked samples

The samples of the keys being masked and the color of the teeth being unknown to the observers, the possibility of obtaining erroneous results was minimized.

\section{Results}

The mean values of the matching time in the case of the determination with Vita Classical were $32.44 \mathrm{~s}$ for 1.1 (Table I); $25.22 \mathrm{~s}$ for 1.2 (Table II) and $20.56 \mathrm{~s}$ for 1.3. (Table III).

Table I. Descriptive statistics 1.1 Vita Classical (time)

\begin{tabular}{|c|c|c|c|c|}
\hline \multicolumn{5}{|l|}{ Vita Classical } \\
\hline Target tooth & & & Statistic & Standard Error \\
\hline 1.1 & \multicolumn{2}{|l|}{ Mean } & 32,44 & 2,753 \\
\hline & \multirow{2}{*}{$\begin{array}{l}95 \% \quad \text { Confidence } \\
\text { Interval for Mean }\end{array}$} & Lower Bound & \multirow{2}{*}{$\begin{array}{l}26,64 \\
38,25\end{array}$} & \\
\hline & & Upper Bound & & \\
\hline & \multicolumn{2}{|l|}{ Median } & 31,5 & \\
\hline & \multicolumn{2}{|l|}{ Std. Deviation } & 11,678 & \\
\hline & \multicolumn{2}{|l|}{ Minimum } & 15 & \\
\hline & \multicolumn{2}{|l|}{ Maximum } & 62 & \\
\hline & \multicolumn{2}{|l|}{ Interquartile Range } & 13 & \\
\hline & \multicolumn{2}{|l|}{ Skewness a } & 0,821 & 0,536 \\
\hline & \multicolumn{2}{|l|}{ Kurtosis } & 1,18 & 1,038 \\
\hline
\end{tabular}

Table II. Descriptive statistics 1.2 Vita Classical (time)

\begin{tabular}{|c|c|c|c|c|}
\hline \multicolumn{5}{|c|}{ Vita Classical } \\
\hline Target tooth & & & Statistic & Standard Error \\
\hline \multirow{3}{*}{1.2} & \multicolumn{2}{|l|}{ Mean } & 25,22 & 1,883 \\
\hline & \multirow{2}{*}{$\begin{array}{l}95 \% \text { Confidence } \\
\text { Interval for } \\
\text { Mean }\end{array}$} & Lower Bound & \multirow{2}{*}{$\begin{array}{l}21,25 \\
29,20\end{array}$} & \\
\hline & & Upper Bound & & \\
\hline
\end{tabular}




\begin{tabular}{|l|l|l|} 
Median & 25 & \\
\hline Std. Deviation & 7,989 & \\
\hline Minimum & 15 & \\
\hline Maximum & 41 & \\
\hline Interquartile Range & 12 & \\
\hline Skewness a & 0,634 & 0,536 \\
\hline Kurtosis & $-0,507$ & 1,038 \\
\hline
\end{tabular}

Table III. Descriptive statistics 1.3 Vita Classical (time)

\begin{tabular}{|c|c|c|c|c|}
\hline \multicolumn{5}{|l|}{ Vita Classical } \\
\hline Target tooth & & & Statistic & Standard Error \\
\hline \multirow[t]{10}{*}{1.3} & \multicolumn{2}{|l|}{ Mean } & 20,56 & 1,856 \\
\hline & \multirow{2}{*}{$\begin{array}{l}\text { 95\% Confidence } \\
\text { Interval for } \\
\text { Mean }\end{array}$} & Lower Bound & \multirow[b]{2}{*}{$\begin{array}{l}16,64 \\
24,47 \\
\end{array}$} & \\
\hline & & Upper Bound & & \\
\hline & \multicolumn{2}{|l|}{ Median } & 21,5 & \\
\hline & \multicolumn{2}{|l|}{ Std. Deviation } & 7,876 & \\
\hline & \multicolumn{2}{|l|}{ Minimum } & 7 & \\
\hline & \multicolumn{2}{|l|}{ Maximum } & 40 & \\
\hline & \multicolumn{2}{|c|}{ Interquartile Range } & 9 & \\
\hline & \multicolumn{2}{|c|}{ Skewness a } & 0,45 & 0,536 \\
\hline & \multicolumn{2}{|l|}{ Kurtosis } & 1,169 & 1,038 \\
\hline
\end{tabular}

The mean values of the matching time in the case of the determination with the Vita Linear Guide were 47.33 s for 1.1 (Table IV); 39.17 s for 1.2 (Table V) and $28.50 \mathrm{~s}$ for 1.3. (Table VI).

Table IV. Descriptive statistics 1.1 Vita Linear Guide (time)

\begin{tabular}{|c|c|c|c|c|}
\hline \multicolumn{5}{|c|}{ Vita Linear Guide } \\
\hline Target tooth & & & Statistic & Standard Error \\
\hline 1.1 & \multicolumn{2}{|l|}{ Mean } & 47,33 & 3,367 \\
\hline & \multirow{2}{*}{$\begin{array}{l}\text { 95\% Confidence } \\
\text { Interval for } \\
\text { Mean }\end{array}$} & Lower Bound & \multirow{2}{*}{$\begin{array}{l}40,23 \\
54,44\end{array}$} & \\
\hline & & Upper Bound & & \\
\hline & \multicolumn{2}{|l|}{ Median } & 50,5 & \\
\hline & \multicolumn{2}{|l|}{ Std. Deviation } & 14,287 & \\
\hline & \multicolumn{2}{|l|}{ Minimum } & 27 & \\
\hline & \multicolumn{2}{|l|}{ Maximum } & 68 & \\
\hline & \multicolumn{2}{|c|}{ Interquartile Range } & 28 & \\
\hline & \multicolumn{2}{|c|}{ Skewness a } & $-0,104$ & 0,536 \\
\hline & \multicolumn{2}{|l|}{ Kurtosis } & $-1,508$ & 1,038 \\
\hline
\end{tabular}


Table V. Descriptive statistics 1.2 Vita Linear Guide (time)

\begin{tabular}{|c|c|c|c|c|}
\hline \multicolumn{5}{|c|}{ Vita Linear Guide } \\
\hline Target tooth & & & Statistic & Standard Error \\
\hline 1.2 & \multicolumn{2}{|l|}{ Mean } & 39,17 & 1,883 \\
\hline & \multirow{2}{*}{$\begin{array}{l}\text { 95\% Confidence } \\
\text { Interval for } \\
\text { Mean }\end{array}$} & Lower Bound & \multirow[b]{2}{*}{$\begin{array}{l}31,74 \\
46,59\end{array}$} & \\
\hline & & Upper Bound & & \\
\hline & \multicolumn{2}{|l|}{ Median } & 39 & \\
\hline & \multicolumn{2}{|l|}{ Std. Deviation } & 14,932 & \\
\hline & \multicolumn{2}{|l|}{ Minimum } & 12 & \\
\hline & \multicolumn{2}{|l|}{ Maximum } & 69 & \\
\hline & \multicolumn{2}{|l|}{ Interquartile Range } & 26 & \\
\hline & \multicolumn{2}{|c|}{ Skewness a } & 0,125 & 0,536 \\
\hline & \multicolumn{2}{|l|}{ Kurtosis } & $-0,625$ & 1,038 \\
\hline
\end{tabular}

Table VI. Descriptive statistics 1.3 Vita Linear Guide (time)

\begin{tabular}{|c|c|c|c|c|}
\hline \multicolumn{5}{|c|}{ Vita Linear Guide } \\
\hline Target tooth & & & Statistic & Standard Error \\
\hline \multirow[t]{10}{*}{1.3} & \multicolumn{2}{|l|}{ Mean } & 28,5 & 2,647 \\
\hline & \multirow{2}{*}{$\begin{array}{l}\text { 95\% Confidence } \\
\text { Interval for } \\
\text { Mean } \\
\end{array}$} & Lower Bound & \multirow[b]{2}{*}{$\begin{array}{l}22,91 \\
34,09 \\
\end{array}$} & \\
\hline & & Upper Bound & & \\
\hline & \multicolumn{2}{|l|}{ Median } & 28,5 & \\
\hline & \multicolumn{2}{|l|}{ Std. Deviation } & 11,232 & \\
\hline & \multicolumn{2}{|l|}{ Minimum } & 10 & \\
\hline & \multicolumn{2}{|l|}{ Maximum } & 58 & \\
\hline & \multicolumn{2}{|l|}{ Interquartile Range } & 15 & \\
\hline & \multicolumn{2}{|l|}{ Skewness a } & 0,729 & 0,536 \\
\hline & \multicolumn{2}{|l|}{ Kurtosis } & 1,583 & 1,038 \\
\hline
\end{tabular}

The mean values of dEab for the determination with Vita Classical were 7.7328 for 1.1 (Table VII); 7.9739 for 1.2 (Table VIII) and 7.5167 for 1.3. (Table IX).

Table VII. Descriptive statistics 1.1 Vita Classical (dEab)

\begin{tabular}{|c|c|c|c|c|}
\hline \multicolumn{5}{|l|}{ Vita Classical } \\
\hline Target tooth & & & Statistic & Standard Error \\
\hline 1.1 & \multicolumn{2}{|l|}{ Mean } & 7,7328 & 0,59589 \\
\hline & \multirow{2}{*}{$\begin{array}{l}95 \% \quad \text { Confidence } \\
\text { Interval for Mean }\end{array}$} & Lower Bound & \multirow{2}{*}{$\begin{array}{l}6,4756 \\
8,99\end{array}$} & \\
\hline & & Upper Bound & & \\
\hline & \multicolumn{2}{|l|}{ Median } & 6,57 & \\
\hline & \multicolumn{2}{|l|}{ Std. Deviation } & 2,52814 & \\
\hline & \multicolumn{2}{|l|}{ Minimum } & 4,6 & \\
\hline & \multicolumn{2}{|l|}{ Maximum } & 11,18 & \\
\hline
\end{tabular}




\begin{tabular}{|l|l|l|l|}
\hline & Interquartile Range & 5,08 & \\
\cline { 2 - 4 } & Skewness a & 0,439 & 0,536 \\
\cline { 2 - 4 } & Kurtosis & $-1,641$ & 1,038 \\
\hline
\end{tabular}

Table VIII. Descriptive statistics 1.2 Vita Classical (dEab)

\begin{tabular}{|c|c|c|c|c|}
\hline \multicolumn{5}{|l|}{ Vita Classical } \\
\hline Target tooth & & & Statistic & Standard Error \\
\hline 1.2 & \multicolumn{2}{|l|}{ Mean } & 7,9739 & 0,51468 \\
\hline & \multirow{2}{*}{$\begin{array}{l}95 \% \quad \text { Confidence } \\
\text { Interval for Mean }\end{array}$} & Lower Bound & \multirow{2}{*}{$\begin{array}{l}6,8880 \\
9,0598\end{array}$} & \\
\hline & & Upper Bound & & \\
\hline & \multicolumn{2}{|l|}{ Median } & 6,73 & \\
\hline & \multicolumn{2}{|l|}{ Std. Deviation } & 2,18362 & \\
\hline & \multicolumn{2}{|l|}{ Minimum } & 5,49 & \\
\hline & \multicolumn{2}{|l|}{ Maximum } & 11,49 & \\
\hline & \multicolumn{2}{|l|}{ Interquartile Range } & 4 & \\
\hline & \multicolumn{2}{|l|}{ Skewness a } & 0,474 & 0,536 \\
\hline & \multicolumn{2}{|l|}{ Kurtosis } & $-1,756$ & 1,038 \\
\hline
\end{tabular}

Table IX. Descriptive statistics 1.3 Vita Classical (dEab)

\begin{tabular}{|c|c|c|c|c|}
\hline \multicolumn{5}{|l|}{ Vita Classical } \\
\hline Target tooth & & & Statistic & Standard Error \\
\hline 1.3 & \multicolumn{2}{|l|}{ Mean } & 7,5167 & 0,77084 \\
\hline & \multirow{2}{*}{$\begin{array}{l}95 \% \text { Confidence } \\
\text { Interval for Mean }\end{array}$} & Lower Bound & \multirow{2}{*}{$\begin{array}{l}5,8903 \\
9,1430\end{array}$} & \\
\hline & & Upper Bound & & \\
\hline & \multicolumn{2}{|l|}{ Median } & 6,07 & \\
\hline & \multicolumn{2}{|l|}{ Std. Deviation } & 3,27038 & \\
\hline & \multicolumn{2}{|l|}{ Minimum } & 5,35 & \\
\hline & \multicolumn{2}{|l|}{ Maximum } & 14,69 & \\
\hline & \multicolumn{2}{|l|}{ Interquartile Range } & 5,43 & \\
\hline & \multicolumn{2}{|l|}{ Skewness a } & 1,415 & 0,536 \\
\hline & \multicolumn{2}{|l|}{ Kurtosis } & 0,66 & 1,038 \\
\hline
\end{tabular}

The mean values of $\mathrm{dEab}$ for the determination with the Vita Linear Guide were 6.9022 for 1.1 (Table X); 6.0356 for 1.2 (Table XI) and 7.4483 for 1.3. (Table XII).

Table X. Descriptive statistics 1.1 Vita Linear Guide (dEab)

\begin{tabular}{|c|c|c|c|c|}
\hline \multicolumn{5}{|c|}{ Vita Linear Guide } \\
\hline Target tooth & & & Statistic & Standard Error \\
\hline 1.1 & \multicolumn{2}{|l|}{ Mean } & 6,9022 & 0,81794 \\
\hline & \multirow{2}{*}{$\begin{array}{l}\text { 95\% Confidence } \\
\text { Interval for } \\
\text { Mean }\end{array}$} & Lower Bound & \multirow[b]{2}{*}{$\begin{array}{l}5,1765 \\
8,6279 \\
\end{array}$} & \\
\hline & & Upper Bound & & \\
\hline & \multicolumn{2}{|l|}{ Median } & 7,48 & \\
\hline & \multicolumn{2}{|l|}{ Std. Deviation } & 3,47022 & \\
\hline & \multicolumn{2}{|l|}{ Minimum } & 2,64 & \\
\hline & \multicolumn{2}{|l|}{ Maximum } & 13,77 & \\
\hline
\end{tabular}




\begin{tabular}{|l|l|l|l|}
\hline \multirow{2}{*}{ Interquartile Range } & 7,19 & \\
\cline { 2 - 4 } & Skewness a & 0,005 & 0,536 \\
\cline { 2 - 4 } & Kurtosis & $-0,929$ & 1,038 \\
\hline
\end{tabular}

Table XI. Descriptive statistics 1.2 Vita Linear Guide (dEab)

\begin{tabular}{|c|c|c|c|c|}
\hline \multicolumn{5}{|c|}{ Vita Linear Guide } \\
\hline Target tooth & & & Statistic & Standard Error \\
\hline 1.2 & \multicolumn{2}{|l|}{ Mean } & 6,0356 & 0,62061 \\
\hline & \multirow{2}{*}{$\begin{array}{l}\text { 95\% Confidence } \\
\text { Interval for } \\
\text { Mean }\end{array}$} & Lower Bound & \multirow[b]{2}{*}{$\begin{array}{l}4,7262 \\
7,3449 \\
\end{array}$} & \\
\hline & & Upper Bound & & \\
\hline & \multicolumn{2}{|l|}{ Median } & 4,11 & \\
\hline & \multicolumn{2}{|l|}{ Std. Deviation } & 2,63301 & \\
\hline & \multicolumn{2}{|l|}{ Minimum } & 4,11 & \\
\hline & \multicolumn{2}{|l|}{ Maximum } & 10,8 & \\
\hline & \multicolumn{2}{|l|}{ Interquartile Range } & 3,96 & \\
\hline & \multicolumn{2}{|l|}{ Skewness a } & 0,85 & 0,536 \\
\hline & \multicolumn{2}{|l|}{ Kurtosis } & $-1,001$ & 1,038 \\
\hline
\end{tabular}

Table XII. Descriptive statistics 1.3 Vita Linear Guide (dEab)

\begin{tabular}{|c|c|c|c|c|}
\hline \multicolumn{5}{|c|}{ Vita Linear Guide } \\
\hline Target tooth & & & Statistic & Standard Error \\
\hline 1.3 & \multicolumn{2}{|l|}{ Mean } & 7,4483 & 0,59039 \\
\hline & \multirow{2}{*}{$\begin{array}{l}95 \% \\
\text { Confidence } \\
\text { Interval for } \\
\text { Mean }\end{array}$} & Lower Bound & \multirow[b]{2}{*}{$\begin{array}{l}6,2027 \\
8,6939\end{array}$} & \\
\hline & & Upper Bound & & \\
\hline & \multicolumn{2}{|l|}{ Median } & 8,16 & \\
\hline & \multicolumn{2}{|l|}{ Std. Deviation } & 2,50481 & \\
\hline & \multicolumn{2}{|l|}{ Minimum } & 2,89 & \\
\hline & \multicolumn{2}{|c|}{ Maximum } & 9,54 & \\
\hline & \multicolumn{2}{|c|}{ Interquartile Range } & 4,95 & \\
\hline & \multicolumn{2}{|c|}{ Skewness a } & $-0,807$ & 0,536 \\
\hline & \multicolumn{2}{|l|}{ Kurtosis } & $-0,992$ & 1,038 \\
\hline
\end{tabular}

The Mann Whitney U test was performed to see if there was a statistically significant difference between the time required to determine the dental color of the three teeth $(1.1 ; 1.2 ; 1.3)$ with the Vita Classical key and the time required to determine the dental color of the three teeth with the Vita Linear Guide key. We also applied the Mann Whitney U test to see if there were statistically significant differences between the 
accuracy of dental color determination with Vita Classical (dEab) and the accuracy of dental color determination with Vita Linear Guide (dEab) (Table XIII, Table XIV).

The results of this test show that there is a statistically significant difference ( $\mathrm{p}<0.05$ ) between the time required to determine tooth color with Vita Classical (mean range $=41.51$ ) and the time required to determine tooth color with Vita Linear Guide (mean range). $=67.49$ ), but this did not lead to a statistically significant difference $(\mathrm{p}>0.05)$ between the accuracy of dental color determination with Vita Classical (mean range $\mathrm{dEab}=60.09$ ) and the accuracy of color determination with Vita Linearguide (mean rank dEab = 48.91) (Table XIII, Table XIV).

These differences show that observers needed more time to determine the color with the Vita Linear Guide key than with the Vita Classical key, but the fact that they needed extra time with the Vita Linear Guide key did not result in more accuracy of the color determination compared to the determinations made with the Vita Classical key.

The difference in matching time between the two keys can be explained in two ways. The Vita Linear Guide key has 29 samples, compared to the 16 of the Vita Classical key and requires more determination steps than the Vita Classical key. Also, observers are more familiar with using the Vita Classical key than using the Vita Linear Guide.

Tabel XIII. Mann Whitney U Test (Ranks)

\begin{tabular}{|c|c|c|c|c|}
\hline \multicolumn{5}{|c|}{ Ranks } \\
\hline \multirow{4}{*}{ Matching time } & Shadeguide & $\mathrm{N}$ & Mean Rank & Sum of Ranks \\
\cline { 2 - 5 } & Vita Classical & 54 & 41,51 & 2241,5 \\
\cline { 2 - 5 } & Vita Linear Guide & 54 & 67,49 & 3644,5 \\
\cline { 2 - 5 } & Total & 108 & & 3245 \\
\hline \multirow{3}{*}{ dEab } & Vita Classical & 54 & 60,09 & 2641 \\
\cline { 2 - 5 } & Vita Linear Guide & 54 & 48,91 & \\
\cline { 2 - 5 } & Total & 108 & & \\
\hline
\end{tabular}

Tabel XIV. Mann Whitney U Test (Statistic)

\begin{tabular}{|c|c|c|}
\hline \multicolumn{3}{|c|}{ Statistic test } \\
\hline & Matching time & $\mathrm{dEab}$ \\
\hline Mann-Whitney U & 756,5 & 1156 \\
\hline Wilcoxon W & 2241,5 & 2641 \\
\hline Z & $-4,313$ & $-1,858$ \\
\hline Asymp Sig (2-tailed) & 0 & 0,063 \\
\hline
\end{tabular}


The Kruskal Wallis test was performed to see if there were statistically significant differences between the time of determination of the three teeth colors with the Vita Classical key. Also with the help of the Kruskal Wallis test, we wanted to determine if there are statistically significant differences between the time of determination of the three teeth colors with the Vita Linear Guide key (Table XV, Table XVI).

The next step was to determine whether in determining the dental color of the three teeth with the same color key (Vita Classical, respectively Vita Linear Guide) there are statistically significant differences in terms of accuracy of determination (dEab) (Table XV, Table XVI).

The results of the Kruskal Wallis test show that there are no statistically significant differences ( $p>0.05$ ) between the accuracy of the dental color determinations of the three teeth with the Vita Classical key. There are also no statistically significant differences ( $>$ > 0.05) between the accuracy of the dental color determinations of the three teeth with the Vita Linear Guide key (Table XV, Table XVI).

Statistically significant differences $(p<0.05)$ were found following the Kruskal Wallis test between the tooth color matching time of the three teeth with the Vita Classical key and also statistically significant differences $(p<0.05)$ were found between the times for determining the dental color of the three teeth with the Vita Linear Guide key (Table XV, Table XVI).

Tabel XV. Kruskal Wallis Test (Ranks)

\begin{tabular}{|c|c|c|c|}
\hline \multirow{2}{*}{ Matching time Vita classical } & Ranks & \multicolumn{2}{|c|}{} \\
\hline \multirow{4}{*}{ Target tooth } & $\mathrm{N}$ & Mean Rank \\
\cline { 2 - 4 } & 1.1 & 18 & 36,78 \\
\cline { 2 - 4 } & 1.2 & 18 & 26,69 \\
\cline { 2 - 4 } & 1.3 & 18 & 19,03 \\
\hline Matching timeVita Linear Guide & Total & 54 & \\
\cline { 2 - 4 } & 1.1 & 18 & 36,44 \\
\cline { 2 - 4 } & 1.2 & 18 & 28,28 \\
\cline { 2 - 4 } & 1.3 & 18 & 17,78 \\
\hline & Total & 54 & \\
\hline dEab Vita Classical & 1.1 & 18 & 28,22 \\
\cline { 2 - 4 } & 1.2 & 18 & 31,11 \\
\cline { 2 - 4 } & 1.3 & 18 & 23,17 \\
\cline { 2 - 4 } & Total & 54 & \\
\hline dEab Vita Linear Guide & 1.1 & 18 & 26,61 \\
\hline
\end{tabular}




\begin{tabular}{|c|c|c|}
\hline 1.2 & 18 & 23,72 \\
\hline 1.3 & 18 & 32,17 \\
\hline Total & 54 & \\
\hline
\end{tabular}

Tabel XVI. Kruskal Wallis Test (Statistic)

\begin{tabular}{|c|c|c|c|c|}
\hline \multicolumn{5}{|c|}{ Statistic test } \\
\hline & $\begin{array}{c}\text { Matching time } \\
\text { Vita Classical }\end{array}$ & $\begin{array}{c}\text { Matching time Vita } \\
\text { Linear Guide }\end{array}$ & $\begin{array}{c}\text { dEab Vita } \\
\text { Classical }\end{array}$ & $\begin{array}{c}\text { dEab Vita } \\
\text { Linear Guide }\end{array}$ \\
\hline Hi squaret & 11,563 & 12,755 & 2,367 & 2,721 \\
\hline df & 2 & 2 & 2 & 2 \\
\hline Asymp. Sig & 0,003 & 0,002 & 0,306 & 0,257 \\
\hline
\end{tabular}

To determine between which of the three teeth included in the study there are statistically significant differences between the tooth color matching times, the Mann Whitney U test was performed, with the teeth tested two by two and for each of the two keys separately.

The Mann Whitney $U$ test was applied to see if there is a statistically significant difference between the time to determine the color of tooth 1.1 and the time to determine the color of tooth 1.2, for each of the two keys, shows that there is a statistically significant difference ( $\mathrm{p}$ $<0.05$ ) between the time of determining the color of tooth 1.1 and the time of determining the color of tooth 1.2 when these determinations were performed with the Vita Classical key, but there is no statistically significant difference ( $>0.05$ ) between the time of determining the color of tooth 1.1 and the time of determining the color of tooth 1.2 when these determinations were performed with the Vita Linear Guide key (Table XVII, Table XVIII).

The fact that there is a statistically significant difference between the determinations of color of teeth 1.1 and 1.2 with the key Vita Classical may be the result of the fact that observers insisted more on the first determination and also the fact that they got used to the technique after determining the first tooth.

Tabel XVII. Mann Whitney U Test 1.1 și 1.2 (Ranks)

\begin{tabular}{|l|l|l|l|l|}
\hline \multicolumn{2}{|l|}{ Ranks } & \multicolumn{5}{l|}{} \\
\hline & Target tooth & $\mathrm{N}$ & Mean Rank & Sum of Ranks \\
\hline \multirow{2}{*}{$\begin{array}{l}\text { Matching time } \\
\text { Classical }\end{array}$} & 1.1 & 18 & 22,11 & 398 \\
\cline { 3 - 6 } & 1.2 & 18 & 14,89 & 268 \\
\cline { 3 - 6 } & Total & 36 & & \\
\hline $\begin{array}{l}\text { Matching time } \\
\text { Linear Guide }\end{array}$ & 1.1 & 18 & 21,47 & 386,5 \\
\cline { 3 - 6 } & 1.2 & 18 & 15,53 & 279,5 \\
\hline
\end{tabular}


Tabel XVIII. Mann Whitney U Test 1.1 și 1.2 (Statistic)

\begin{tabular}{|c|c|c|}
\hline \\
\hline Statistic test & \begin{tabular}{l|l}
$\begin{array}{l}\text { Matching time Vita } \\
\text { classical }\end{array}$ \\
\end{tabular} & \multirow{2}{*}{ Guide } \\
\hline \multirow{2}{*}{$\begin{array}{l}\text { Mann-Whitney U } \\
\text { Wilcoxon W }\end{array}$} & 97 & \\
\hline & 268 & 279,5 \\
\hline \multirow{2}{*}{$\begin{array}{l}\text { Z } \\
\text { Asymp. Sig (2-tailed) }\end{array}$} & $-2,06$ & $-1,694$ \\
\hline & 0,039 & 0,09 \\
\hline Exact Sig. [2(1-tailed Sig) & 0,04 & 0,091 \\
\hline
\end{tabular}

The Mann Whitney U test applied to see if there is a statistically significant difference between the time of determining the tooth color of tooth 1.1 and the time of determining the tooth color of tooth 1.3, for each of the two keys, shows that there is a statistically significant difference ( $\mathrm{p}<0.05$ ) between the time of determining the color of tooth 1.1 and the time of determining the color of tooth 1.3 when these determinations were made with the Vita Classical key and also shows us that there is a statistically significant difference $(p<0.05)$ between the time of determining the dental color of tooth 1.1 and the time of determining the dental color of tooth 1.3 when these determinations were performed with the key Vita Linear Guide (Table XIX, Table XX).

These differences can be explained by the fact that at the third determination with both keys, the observer is already accustomed to the determination technique and thus the process proceeds faster.

Tabel XIX. Mann Whitney U Test 1.1 și 1.3 (Ranks)

\begin{tabular}{|c|c|c|c|c|}
\hline \multicolumn{5}{|c|}{ Ranks } \\
\hline & Target tooth & $\mathrm{N}$ & Mean Rank & Sum of Ranks \\
\hline \multirow{2}{*}{$\begin{array}{c}\text { Matching time Vita } \\
\text { Classical }\end{array}$} & 1.1 & 18 & 24,17 & 435 \\
\cline { 2 - 5 } & 1.3 & 18 & 12,83 & 231 \\
\cline { 2 - 5 } & Total & 36 & & \\
\hline $\begin{array}{c}\text { Matching time Vita } \\
\text { Linear Guide }\end{array}$ & 1.1 & 18 & 24,47 & 440,5 \\
\cline { 2 - 5 } & 1.3 & 18 & 12,53 & 225,5 \\
\cline { 2 - 5 } & Total & 36 & & \\
\hline
\end{tabular}

Tabel XX. Mann Whitney U Test 1.1 și 1.3 (Statistic)

\begin{tabular}{|l|c|c|}
\hline \multicolumn{3}{|c|}{ Statistic test } \\
\hline & $\begin{array}{c}\text { Matching time Vita } \\
\text { Classical }\end{array}$ & $\begin{array}{c}\text { Matching time Vita } \\
\text { Linear Guide }\end{array}$ \\
\hline
\end{tabular}




\begin{tabular}{|c|c|c|} 
Mann-Whitney U & 60 & 54,5 \\
\hline Wilcoxon W & 231 & 225,5 \\
\hline Z & $-3,232$ & $-3,405$ \\
\hline Asymp. Sig (2-tailed) & 0,001 & 0,001 \\
\hline Exact Sig. [2(1-tailed Sig)] & 0,001 & 0 \\
\hline
\end{tabular}

The Mann Whitney U test applied to see if there is a statistically significant difference between the time to determine the color of tooth 1.2 and the time to determine the color of tooth 1.3, for each of the two keys, shows that there is no statistically significant difference. ( $>>0.05$ ) between the time of determining the color of tooth 1.1 and the time of determining the color of tooth 1.3 when these determinations were performed with the Vita Classical key, but there is a statistically significant difference $(\mathrm{p}<0.05)$ between the time of determining the color of tooth 1.2 and the time of determining the color of tooth 1.3 when these determinations were performed with the Vita Linear Guide key (Table XXI, Table XXII).

Tabel XXI. Mann Whitney U Test 1.2 și 1.3 (Ranks)

\begin{tabular}{|c|c|c|c|c|}
\hline \multicolumn{5}{|c|}{ Ranks } \\
\hline & Target tooth & $\mathrm{N}$ & Mean Rank & Sum of Ranks \\
\hline \multirow{3}{*}{$\begin{array}{c}\text { Matching time Vita } \\
\text { Classical }\end{array}$} & 1.2 & 18 & 21,31 & 383,5 \\
\cline { 2 - 5 } & 1.3 & 18 & 15,69 & 282,5 \\
\cline { 2 - 5 } & Total & 36 & & \\
\hline \multirow{2}{*}{$\begin{array}{c}\text { Matching time Vita } \\
\text { Linear Guide }\end{array}$} & 2 & 18 & 22,25 & 400,5 \\
\cline { 2 - 5 } & 3 & 18 & 14,75 & 265,5 \\
\cline { 2 - 5 } & Total & 36 & & \\
\hline
\end{tabular}

Tabel XXII. Mann Whitney U Test 1.2 și 1.3 (Statistic)

\begin{tabular}{|c|c|c|}
\hline \multicolumn{3}{|c|}{ Statistic test } \\
\hline & $\begin{array}{c}\text { Matching time Vita } \\
\text { Classical }\end{array}$ & $\begin{array}{c}\text { Matching time Vita } \\
\text { Linear Guide }\end{array}$ \\
\hline Mann-Whitney U & 111,5 & 94,5 \\
\hline Wilcoxon W & 282,5 & 265,5 \\
\hline Z & $-1,602$ & $-2,138$ \\
\hline Asymp. Sig (2-tailed) & 0,109 & 0,033 \\
\hline Exact Sig. [2(1-tailed Sig)] & 0,111 & 0,031 \\
\hline
\end{tabular}

For each tooth, the Spearman correlation coefficients were calculated between the time required to determine the tooth color of each 
tooth and the accuracy of the determination. Thus we can see if time influences the final result of the determination.

In the case of tooth 1.1, both with the Vita Classical key and with the Vita Linear Guide key, no statistically significant correlation was found between the tooth color matching time and the matching accuracy. In other words, even if some observers needed extra time than others, it does not mean that they determined more correctly the color of tooth 1.1 (Table XXIII, Table XXIV).

Tabel XXIII. Spearman correlation coefficient 1.1 Vita Classical

\begin{tabular}{|c|c|c|c|c|}
\hline \multicolumn{5}{|c|}{ Correlations } \\
\hline & & & $\begin{array}{l}\text { Matching time } \\
\text { Vita Classical }\end{array}$ & $\begin{array}{c}\text { dEab Vita } \\
\text { Classical } \\
\end{array}$ \\
\hline \multirow[t]{6}{*}{$\begin{array}{c}\text { Spearman } \\
\text { Coefficient }\end{array}$} & \multirow[t]{3}{*}{$\begin{array}{l}\text { Matching time } \\
\text { Vita Classical }\end{array}$} & $\begin{array}{l}\text { Correlation } \\
\text { coefficient }\end{array}$ & 1 & 0,37 \\
\hline & & Sig. (2-tailed) & & 0,131 \\
\hline & & $\mathrm{N}$ & 18 & 18 \\
\hline & \multirow[t]{3}{*}{$\begin{array}{l}\text { dEab Vita } \\
\text { Classical }\end{array}$} & $\begin{array}{l}\text { Correlation } \\
\text { coefficient } \\
\end{array}$ & 0,37 & 1 \\
\hline & & Sig. (2-tailed) & 0,131 & \\
\hline & & $\mathrm{N}$ & 18 & 18 \\
\hline
\end{tabular}

Tabel XXIV. Spearman correlation coefficient 1.1 Vita Linear Guide

\begin{tabular}{|c|c|c|c|c|}
\hline \multicolumn{5}{|c|}{ Correlations } \\
\hline & & & $\begin{array}{l}\text { Matching time Vita } \\
\text { Linear Guide }\end{array}$ & $\begin{array}{c}\text { dEab Vita } \\
\text { Linear } \\
\text { Guide } \\
\end{array}$ \\
\hline \multirow[t]{6}{*}{$\begin{array}{l}\text { Spearman } \\
\text { Coefficient }\end{array}$} & \multirow{3}{*}{$\begin{array}{l}\text { Matching time } \\
\text { Vita Linear } \\
\text { Guide }\end{array}$} & $\begin{array}{l}\text { Correlation } \\
\text { coefficient }\end{array}$ & 1 & 0,138 \\
\hline & & Sig. (2-tailed) & & 0,584 \\
\hline & & $\mathrm{N}$ & 18 & 18 \\
\hline & \multirow[t]{3}{*}{$\begin{array}{c}\text { dEab Vita } \\
\text { Linear Guide }\end{array}$} & $\begin{array}{l}\text { Correlation } \\
\text { coefficient }\end{array}$ & 0,138 & 1 \\
\hline & & Sig. (2-tailed) & 0,584 & \\
\hline & & $\mathrm{N}$ & 18 & 18 \\
\hline
\end{tabular}

As with tooth 1.1 and tooth 1.2, both with the Vita Classical key and with the Vita Linear Guide key, no statistically significant correlation was found between the tooth color matching time and the matching accuracy. In other words, even if some observers needed extra time than others, it does not mean that they determined the color of tooth 1.2 more correctly (Table XXV, Table XXVI) 
Tabel XXV. Spearman correlation coefficient 1.2 Vita Classical

\begin{tabular}{|c|c|c|c|c|}
\hline \multicolumn{2}{|c|}{} & & $\begin{array}{c}\text { Correlations } \\
\text { Classical }\end{array}$ & $\begin{array}{c}\text { dEab Vita } \\
\text { Classical }\end{array}$ \\
\hline \multirow{3}{*}{$\begin{array}{c}\text { Spearman } \\
\text { Coefficient }\end{array}$} & $\begin{array}{c}\text { Matching time } \\
\text { Vita Classical }\end{array}$ & $\begin{array}{c}\text { Correlation } \\
\text { coefficient }\end{array}$ & 1 & $-0,074$ \\
\cline { 3 - 5 } & & Sig. (2-tailed) & & 0,771 \\
\cline { 3 - 5 } & & $\mathrm{N}$ & 18 & 18 \\
\cline { 3 - 5 } & \multirow{4}{*}{$\begin{array}{c}\text { dEab Vita } \\
\text { Classical }\end{array}$} & $\begin{array}{c}\text { Correlation } \\
\text { coefficient }\end{array}$ & $-0,074$ & 1 \\
\cline { 3 - 5 } & & Sig. (2-tailed) & 0,771 & 18 \\
\cline { 3 - 5 } & & $\mathrm{N}$ & 18 & \\
\cline { 3 - 5 } & & & &
\end{tabular}

Tabel XXVI. Spearman correlation coefficient 1.2 Vita Linear Guide

\begin{tabular}{|c|c|c|c|c|}
\hline \multicolumn{5}{|c|}{ Correlations } \\
\hline & & & $\begin{array}{l}\text { Matching time Vita } \\
\text { Linear Guide }\end{array}$ & $\begin{array}{c}\text { dEab Vita } \\
\text { Linear } \\
\text { Guide }\end{array}$ \\
\hline \multirow[t]{6}{*}{$\begin{array}{l}\text { Spearman } \\
\text { Coefficient }\end{array}$} & \multirow{3}{*}{$\begin{array}{l}\text { Matching time } \\
\text { Vita Linear } \\
\text { Guide }\end{array}$} & $\begin{array}{l}\text { Correlation } \\
\text { coefficient }\end{array}$ & 1 & $-0,238$ \\
\hline & & Sig. (2-tailed) & & 0,341 \\
\hline & & $\mathrm{N}$ & 18 & 18 \\
\hline & \multirow[t]{3}{*}{$\begin{array}{c}\text { dEab Vita } \\
\text { Linear Guide }\end{array}$} & $\begin{array}{l}\text { Correlation } \\
\text { coefficient }\end{array}$ & $-0,238$ & 1 \\
\hline & & Sig. (2-tailed) & 0,341 & \\
\hline & & $\mathrm{N}$ & 18 & 18 \\
\hline
\end{tabular}

The results of the correlation tests performed on the determinations of tooth 1.3, to determine the correlation between the accuracy of the determination and the matching time, do not show any statistically significant correlation between them both in the determination with the Vita Classical key and in the determination with the Vita Linear Guide key. The fact that the observers determined the tooth color for a longer time did not lead to a higher accuracy of the determination (Table XXVII, Table XXVIII).

Tabel XXVII. Spearman correlation coefficient 1.3 Vita Classical

\begin{tabular}{|c|c|c|c|c|}
\hline \multicolumn{2}{|c|}{ Correlations } \\
\hline \multirow{2}{*}{$\begin{array}{c}\text { Spearman } \\
\text { Coefficient }\end{array}$} & $\begin{array}{c}\text { Matching time } \\
\text { Vita Classical }\end{array}$ & $\begin{array}{c}\text { Correlation } \\
\text { coefficient }\end{array}$ & $\begin{array}{c}\text { Matching time Vita } \\
\text { Classical }\end{array}$ & $\begin{array}{c}\text { dEab Vita } \\
\text { Classical }\end{array}$ \\
\cline { 3 - 5 } & & Sig. (2-tailed) & 1 & 0,17 \\
\cline { 3 - 5 } & & $\mathrm{N}$ & 18 & 0,5 \\
\hline
\end{tabular}




\begin{tabular}{|l|c|c|c|c|}
\multirow{4}{*}{$\begin{array}{c}\text { dEab Vita } \\
\text { Classical }\end{array}$} & $\begin{array}{c}\text { Correlation } \\
\text { coefficient }\end{array}$ & 0,17 & 1 \\
\cline { 3 - 5 } & Sig. (2-tailed) & 0,5 & \\
\cline { 2 - 5 } & $\mathrm{N}$ & 18 & 18 \\
\hline
\end{tabular}

Tabel XXVIII. Spearman correlation coefficient 1.3 Vita Linear Guide

\begin{tabular}{|c|c|c|c|c|}
\hline \multicolumn{5}{|c|}{ Correlations } \\
\hline & & & $\begin{array}{l}\text { Matching time Vita } \\
\text { Linear Guide }\end{array}$ & $\begin{array}{c}\text { dEab Vita } \\
\text { Linear } \\
\text { Guide }\end{array}$ \\
\hline \multirow[t]{6}{*}{$\begin{array}{l}\text { Spearman } \\
\text { Coefficient }\end{array}$} & \multirow{3}{*}{$\begin{array}{l}\text { Matching time } \\
\text { Vita Linear } \\
\text { Guide }\end{array}$} & $\begin{array}{c}\text { Correlation } \\
\text { coefficient }\end{array}$ & 1 & 0,27 \\
\hline & & Sig. (2-tailed) & & 0,278 \\
\hline & & $\mathrm{N}$ & 18 & 18 \\
\hline & \multirow[t]{3}{*}{$\begin{array}{c}\text { dEab Vita } \\
\text { Linear Guide }\end{array}$} & $\begin{array}{c}\text { Correlation } \\
\text { coefficient }\end{array}$ & 0,27 & 1 \\
\hline & & Sig. (2-tailed) & 0,278 & \\
\hline & & $\mathrm{N}$ & 18 & 18 \\
\hline
\end{tabular}

\section{Discusions}

The results of the statistical tests, applied to test the first hypothesis, show that for color A3 (tooth 1.1) a longer matching time was required than A2 (tooth 1.2) and A3.5 (tooth1.3) when the determination was performed with Vita Classical and a longer matching time for 2M2 (tooth 1.1) than 3M2 (tooth 1.3) but not longer to tooth 1.2 (color 2M2) when the determination was performed with the Vita Linear Guide. It also took a longer time to determine 2M2 (tooth 1.2) than 3M2 (tooth 1.3) when the determination was made with the Vita Linear Guide. These results show that A3 is a color more difficult to determine than A2 and A3.5. We can also deduce that 2M2 is a color that requires more time to determine than $3 \mathrm{M} 2$. It should be noted that tooth 1.1 of color A3 (2M2) was the first tooth determined with both keys and observers tend to insist more on the first determination. At the same time, there was no statistically significant difference between the matching times between 1.1 and 1.2 with the Vita Linear Guide key as they had the same color.

For the second hypothesis, the results of the statistical tests show that there is no statistically significant difference between the accuracy of the tooth color determination between the three samples A3 (tooth 1.1), A2 (tooth 1.2) and A3.5 (tooth 1.3) in the determinations performed with Vita Classical. At the same time, there is no statistically significant difference between the accuracy of determining the dental color between the three samples 2M2 (tooth 1.1), $2 \mathrm{M} 2$ (tooth 1.2) and 3M2 (tooth 1.3), in the determinations made 
with Vita Linear Guide. It should be noted that the samples (the patient's teeth) were of similar colors, with the same basic shade.

With regard to the third hypothesis, the results of the statistical tests show that there is no statistically significant correlation between the time required for observers to determine the color of each sample and the accuracy of the determination. Although it took longer to determine the color of A3 and 2M2, they were not determined with a lower accuracy than A2 and A3.5 and 3M2.

The statistical results regarding the fourth hypothesis show that the determination with the Vita Linear Guide key required a statistically significantly longer matching time than the matching time required with the Vita Classical. At the same time we can observe from these results that although the matching time was longer with the Vita Linear Guide, the accuracy of the determinations was similar. It should be noted that Vita Classical has 16 samples arranged linearly, the color being determined globally, and Vita Linear Guide presents 29 samples arranged linearly in 5 categories depending on brightness and has more steps needed to determine the tooth color than Vita Classical. At the same time, observers are more familiar with Vita Classical than Vita Linear Guide. These features can influence the matching time with Vita Linear Guide.

\section{Conclusion:}

1. A3 color required a longer matching time than A2 and A3.5, however the differences were not statistically significant. 2M2 also required a longer matching time than 3M2, but the differences were not statistically significant.

2. The accuracy of color determination (A2, A3, A3.5 and 2M2, 3M2, respectively) was not significantly different for the teeth evaluated in the present study.

3. No correlation was found between the time required to determine a color and the accuracy of its determination.

4. Determination with the Vita Linear Guide requires a longer matching time than the Vita Classical, but no differences were found in the accuracy of color determination with the two color keys (Vita Classical, Vita Linear Guide).

5. The future research directions of this study may be the inclusion of more dental colors in the study and the inclusion of more observers with experience in color matching. 


\section{References:}

1. Paravina R. D. (2009). Performance assessment of dental shade guides. Journal of dentistry, 37 Suppl 1, e15-e20. https://doi.org/10.1016/j.jdent.2009.02.005

2. Dancy, W. K., Yaman, P., Dennison, J. B., O'Brien, W. J., \& Razzoog, M. E. (2003). Color measurements as quality criteria for clinical shade matching of porcelain crowns. Journal of esthetic and restorative dentistry : official publication of the American Academy of Esthetic Dentistry ... [et al.], 15(2), 114-122. https://doi.org/10.1111/j.17088240.2003.tb00327.x

3. Chu, S. J., Trushkowsky, R. D., \& Paravina, R. D. (2010). Dental color matching instruments and systems. Review of clinical and research aspects. Journal of dentistry, 38 Suppl 2, e2-e16. https://doi.org/10.1016/j.jdent.2010.07.001

4. McCullock, A. J., \& McCullock, R. M. (1999). Communicating shades: a clinical and technical perspective. Dental update, 26(6), 247-252. https://doi.org/10.12968/denu.1999.26.6.247

5. Miller L. L. (1993). Shade matching. Journal of esthetic dentistry, 5(4), 143-153. https://doi.org/10.1111/j.17088240.1993.tb00771.x

6. 6. Capa, N., Malkondu, O., Kazazoglu, E., \& Calikkocaoglu, S. (2010). Evaluating factors that affect the shade-matching ability of dentists, dental staff members and laypeople. Journal of the American Dental Association (1939), 141(1), 71-76. https://doi.org/10.14219/jada.archive.2010.0023 